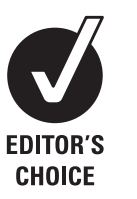

(t)

\begin{abstract}
- An additional appendix is published online only. To view this file please visit the journal online (http://heart.bmj.com/ content/98/8.toc).

1 Department of Epidemiology, University of Wales College of Medicine Heath Park, Cardiff, UK

${ }^{2}$ Research Team for Care of Elderly People, University of Wales College of Medicine, Llandough Hospital, Cardiff, UK ${ }^{3}$ Department of Cardiology, University of Wales College of Medicine Heath Park, Cardiff, UK
\end{abstract}

See Editorial, p 607

\section{Correspondence to}

Professor Robert West, Wales Heart Research Institute, Cardiff University, Heath Park, Cardiff CF14 4XN, UK:

westrr@cardiff.ac.uk

University of Wales College of Medicine has been renamed Cardiff University.

RAMIT Investigators, Cardiff University.

Accepted 17 October 2011 Published Online First 22 December 2011

\title{
Rehabilitation after myocardial infarction trial (RAMIT): multi-centre randomised controlled trial of comprehensive cardiac rehabilitation in patients following acute myocardial infarction
}

\author{
Robert R West, ${ }^{1}$ Dee A Jones, ${ }^{2}$ Andrew H Henderson ${ }^{3}$
}

\begin{abstract}
Background It is widely believed that cardiac rehabilitation following acute myocardial infarction (MI) reduces mortality by approximately $20 \%$. This belief is based on systematic reviews and meta-analyses of mostly small trials undertaken many years ago. Clinical management has been transformed in the past 30-40 years and the findings of historical trials may have little relevance now.

Objectives The principal objective was to determine the effect of cardiac rehabilitation, as currently provided, on mortality, morbidity and health-related quality of life in patients following MI. The secondary objectives included seeking programmes that may be more effective and characteristics of patients who may benefit more.
\end{abstract}

Design, setting, patients, outcome measures $A$ multi-centre randomised controlled trial in representative hospitals in England and Wales compared 1813 patients referred to comprehensive cardiac rehabilitation programmes or discharged to 'usual care' (without referral to rehabilitation). The primary outcome measure was all-cause mortality at 2 years. The secondary measures were morbidity, health service use, healthrelated quality of life, psychological general well-being and lifestyle cardiovascular risk factors at 1 year. Patient entry ran from 1997 to 2000, follow-up of secondary outcomes to 2001 and of vital status to 2006. A parallel study compared 331 patients in matched 'elective' rehabilitation and 'elective' usual care (without rehabilitation) hospitals.

Results There were no significant differences between patients referred to rehabilitation and controls in mortality at 2 years ( $\mathrm{RR} 0.98,95 \% \mathrm{Cl} 0.74$ to 1.30 ) or after 7-9 years $(0.99,95 \% \mathrm{Cl} 0.85$ to 1.15$)$, cardiac events, seven of eight domains of the health-related quality of life scale ('Short Form 36', SF36) or the psychological general well-being scale. Rehabilitation patients reported slightly less physical activity. No differences between groups were reported in perceived overall quality of cardiac aftercare. Data from the 'elective' hospitals comparison concurred with these findings.

Conclusion In this trial, comprehensive rehabilitation following Ml had no important effect on mortality, cardiac or psychological morbidity, risk factors, health-related quality of life or activity. This finding is consistent with systematic reviews of all trials reported since 1983. The value of cardiac rehabilitation as practised in the UK is open to question.

\section{INTRODUCTION}

Cardiac rehabilitation was defined in the late 1960 s as the sum of activities required 'to help patients regain as near normal a place in society as possible following a cardiac event'. ${ }^{1}$ Over the past 40 years it has been accepted that rehabilitation plays an important role in the overall clinical management of cardiac patients, on evidence that it reduces cardiac mortality and morbidity. ${ }^{2-4}$ Initially developed as exercise training and, independently, in psychological therapy or counselling for anxiety and depression for patients following acute myocardial infarction (MI), cardiac rehabilitation is now offered following other acute and chronic coronary syndromes and interventions. Modern 'comprehensive' cardiac rehabilitation focuses on exercise training, health education, advice and support to alter lifestyles to reduce cardiovascular risk and some psychological counselling. Although varying somewhat between centres a 'standard' programme (in UK) is outpatient-based, usually once weekly for 6-10 weeks.

The evidence for cardiac rehabilitation, cited by the most current guidelines, is a $20 \%$ reduction in all-cause mortality reported in systematic reviews. However, this figure is based largely on trials undertaken more than 30 years ago. The WHO European multi-centre collaborative trial, the only relatively large trial in the early 1970s, reported in 1983 the results for 2605 patients in 17 (of 24) centres and concluded that the trial failed to provide an answer to the question of whether comprehensive programmes could reduce mortality and morbidity after acute myocardial infarction'. Subsequent reviews pooled selected centres from the WHO collaborative trial, the US 'national' trials and other smaller trials, undertaken during the 1960s and 1970s, and reported significant mortality reduction. ${ }^{7}$ The more recent Cochrane review in 2000 found a reduction in all-cause mortality in 12 'exercise only' trials $(\mathrm{OR}=0.74,95 \%$ CI 0.56 to 0.98 ) but not in 28 'exercise-plus' (or 'comprehensive') trials ( $\mathrm{OR}=0.87,95 \%$ CI 0.71 to $1.05)^{8}$; subsequently these were combined for an overall $\mathrm{OR}=0.80$ (95\% CI 0.68 to 0.93$).{ }^{9}$ However, a pooling of all those trials in the Cochrane review, that were published after the WHO trial (1983), shows mortality marginally increased with rehabilitation $(R R=1.06$, 95\% CI 0.76 to 1.47$) .{ }^{10}$ Any review that includes early trials remains heavily 
weighted by early trials, when mortality was high. Radical changes in the clinical management of MI-with the introduction of coronary care units (c. 1970), ${ }^{11}$ early mobilisation $(1975)^{12}{ }^{13}$ thrombolysis $(1990)^{14}$ and primary angioplasty $(2000)^{15}$ and in secondary prevention with aspirin (1980), ${ }^{16}$ $\beta$-blockers (1985), ${ }^{17}$ ACE-inhibitors $(1995)^{18}$ and statins $(1994)^{19}$ - have so altered the context of cardiac rehabilitation as to prompt questions about the current validity of conclusions drawn on reviews based largely on historical trials.

Fewer trials have reported outcome in terms of other potential benefits of rehabilitation. Non-fatal myocardial re-infarction was reported in 26 of the 40 trials in the Cochrane review, with no significant reduction $(\mathrm{RR}=0.88,95 \% \mathrm{CI} 0.70$ to 1.12$) .{ }^{9}$ Modest improvements in maximum heart rate and workload were reported in the WHO trial but only in men under the age of 59 years. ${ }^{5}$ Physical working capacity does not necessarily lead to physical activity and trials have not reported beneficial effects in activities of daily living. Evidence that rehabilitation might reduce serum cholesterol, blood pressure or smoking is weak. Only 9 of the 40 trials in the Cochrane review reported serum cholesterol and an effect could have been attributed to cholesterol-lowering medication, which was not recorded. Only five trials reported blood pressure, with a small significant reduction in systolic but not in diastolic pressure. Eight trials reported on smoking, with a favourable but non-significant trend. Eleven trials reported 'health-related quality of life' but quantitative analysis was precluded by the variety of different measures used. $^{8}$

In 1996, pre-dating the reviews that underpin current guidelines and recognising that available evidence of effectiveness was relatively weak in the context of modern clinical management, the newly formed National Health Service (NHS) Research and Development Programme commissioned this controlled trial of comprehensive cardiac rehabilitation.

\section{METHODS}

This multi-centre randomised controlled trial of patients following acute MI was designed to determine the effect of comprehensive cardiac rehabilitation on mortality, morbidity, health-related quality of life, risk factors and activity in the context of modern medical practice. Following a survey of all cardiac rehabilitation provision throughout England, Wales and Scotland, centres with established programmes were selected and invited to participate, if the programmes were multifactorial (including exercise, education and counselling), involved more than one discipline, provided a minimum of $10 \mathrm{~h}$ and would accept randomisation. The survey also identified hospitals with established programmes and unwilling to randomise patients out of rehabilitation and hospitals unable to offer rehabilitation, which were potentially eligible for selection and invitation to participate as 'elective hospitals' (see below).

\section{Patient entry}

The entry criteria were admission to hospital with a principal primary diagnosis of acute MI (two of the three standard criteria 'typical history', electrocardiographic features and cardiac enzymes), discharged home within 28 days, local resident and able to give informed consent-with no age or gender restrictions. Exclusion criteria (recorded) were physical frailty, mental confusion, serious co-existing disease, communication difficulty, previous cardiac rehabilitation and discharged to hospice or another hospital. Eligible patients were informed about the trial and told to expect a home visit by a locally based trial researcher. This researcher visited within days of discharge, described the trial and sought written informed consent before conducting the baseline interview.

\section{Randomisation}

Patients were randomised centrally on a preset protocol, daily and blind as to entry characteristics and baseline measures, on receipt of advice from a locally based researcher that a patient had consented. The names of those randomised to rehabilitation were passed to the local programme coordinator.

\section{Rehabilitation programmes}

Rehabilitation programmes conformed to guidelines issued by the British Association for Cardiac Rehabilitation for phase three (outpatient) rehabilitation. ${ }^{20}$ The programmes comprised exercise training, health education about heart, heart disease, risk factors and treatment, counselling for recovery and advice for long-term secondary prevention. Exercise training was the largest component, typically occupying half of the available time including warm up and cool down, and used exercise equipment in physiotherapy gyms. Relaxation was primarily physical following 'cooling down' from exercise with little or no 'stress management' training. Programmes in most centres were led by nurses with previous acute cardiac care experience and in a few by occupational therapists or physiotherapists. All involved at least one other discipline (exercise physiologist, dietician, pharmacist, health promotion specialist, psychologist, counsellor, social worker, physician and/or cardiologist). They took place weekly or bi-weekly and averaged 20 h over 6-8 weeks. Cardiac arrest facilities were available on site.

All patients in the trial (and in the 'elective hospitals' comparison) had similar care in all respects other than referral to cardiac rehabilitation, receiving available explanatory booklets, being advised to see their general practitioner (GP) and attend routine outpatient follow-up, with referral for further cardiac investigations or interventions as appropriate. Patients were free to attend local patient support groups, which were independent of the programme under evaluation. Hospitals were asked to minimise inpatient rehabilitation and avoid 'advertising' the rehabilitation programme to inpatients.

\section{Baseline measures}

Baseline measures comprised a clinical summary and structured interview. Clinical data included date of birth, date of admission, confirmation of MI diagnosis, site of infarct, peak cardiac enzyme, defibrillation, thrombolysis, emergency angioplasty or surgery, heart failure, cardiogenic shock (systolic blood pressure $<90 \mathrm{~mm} \mathrm{Hg}$ ), late arrhythmia or conduction defect, and history of previous MI, angina, hypertension (blood pressure $>160 / 90 \mathrm{~mm} \mathrm{Hg}$ ) and diabetes. The structured interview used standard measures-Short Form 36 (SF36), a generic health-related quality of life measure with eight domains (physical functioning, role-physical, role-emotional, social functioning, mental health, energy/vitality, pain and health perception, all scored positively, ie, higher scores indicating better health), ${ }^{21-23}$ a measure of psychological general well-being (PGWB) (anxiety, depression and positive well-being), ${ }^{24}$ smoking, ${ }^{25}$ alcohol, $^{26}$ diet $^{27}$ and physical activity. ${ }^{28} 29$ The interviewer also assessed the patient's attitude to life on a fourpoint scale.

\section{Outcome measures}

The primary endpoint was mortality at 2 years, notified by the hospital, GP, spouse, relative or neighbour or the NHS central registry. Late mortality after $7-9$ years was traced at the NHS 
central registry. The date and cause of death were verified at the NHS central registry.

Secondary outcomes were assessed at 1 year by structured interview by a locally based research interviewer (as at baseline), blind to rehabilitation status. These were morbidity (further MI, cerebrovascular accident and revascularisation), health-related quality of life (SF36), PGWB, smoking, alcohol, diet and physical exercise. The interview schedule also recorded medication (aspirin, ACE inhibitors, $\beta$-blockers, diuretics, nitrates and statins), hospital admission for cardiovascular disease, recent (in past 4 weeks) angina, recent (in past 4 weeks) GP visit, employment and financial consequences of illness. Interviewers asked patients not to disclose their rehabilitation status until these standard questions had been answered. Patient's views of cardiac aftercare and rehabilitation, whether or not referred to the programme under evaluation, were sought by structured questions on perceived adequacy of advice, support and training in 11 areas (information on heart disease, risk factors, medication, diet, alcohol, sexual activity, smoking, exercise, relaxation, stress management and cardio-pulmonary resuscitation). At the end of the interview, patients were asked whether or not they had attended the rehabilitation programme under evaluation, any other rehabilitation programme or 'self help' group, and how many sessions of each they attended.

At 2 years, a telephone follow-up of patients recruited in the first year of the randomised trial enquired into readmission, recent angina, statin medication, smoking, general health, change in health in past year, and opinion of overall care and support after index admission.

\section{Elective hospitals comparison}

As a pragmatic evaluation of an existing and growing service, recognising that some hospitals already referred $>50 \%$ of eligible patients to rehabilitation and might consider it unethical to 'withhold' referral and that others had no provision, and to increase the sample size, an 'elective hospital' comparison was designed into the trial from the outset. Pairs of 'elective rehabilitation' and 'elective control' hospitals were matched on standard mortality ratio and socioeconomic classification of their catchment populations, and hospital size, classification and cardiology staffing. All eligible consenting patients in 'elective rehabilitation' hospitals were referred to rehabilitation and in 'elective control' hospitals were allocated to the control group, following the same entry criteria as in the randomised trial, and all were interviewed at baseline and at 12-month follow-up and traced at the NHS central register. This comparison provides less reliable but nonetheless complimentary evidence.

\section{Sample size and analyses}

The sample size needed to demonstrate a significant difference in the primary outcome measure of all-cause mortality at 2 years was estimated as 8000 , based on the $20 \% \mathrm{RR}$ reduction indicated in the reviews of previous trials ${ }^{70}$ and the 2-year all-cause mortality of $11 \%$ in the mid-1990s ( $\alpha=0.05$ and $\beta=0.90$ ). The estimate for the corresponding number for a 'combined cardiovascular endpoint' (mortality, further MI, cerebrovascular accident or revascularisation) was 4000 and to show a difference between rehabilitation and control groups in scale 'physical functioning' (SF36) the estimate for a quarter of the change between baseline and follow-up was 1500 . For practical purposes it was agreed with sponsors that the trial would aim to randomise 3000 vs 3000 patients and compare 1000 vs 1000 in matched pairs of 'elective' hospitals. However, the sponsors subsequently requested early closure-in 2000 (see discussion).
The results are presented in accordance with the Consolidated Standards of Reporting Trials guidelines and analysis is by 'intention to treat'. Results are shown as mean (SD) or as proportions, and comparisons are by $t$ test, $\chi^{2}$ test or Mann-Witney test as appropriate. Mortality is estimated by the Kaplan-Meier method and comparisons are by the log rank test. The findings of the elective comparisons are presented alongside those of the randomised trial and after checking for homogeneity may be combined to enlarge the sample size.

\section{Ethical approval}

Ethical approval was granted in the district of the trial coordinating centre and at the European ethical review committee, and subsequently at UK multi-centre research ethics committee, when that was established, and at districts of participating hospitals.

\section{RESULTS}

One thousand eight hundred and thirteen patients were admitted to the randomised controlled trial between August 1997 and April 2000 in 14 hospitals; 903 to rehabilitation and 910 to control. An additional 331 patients were entered in two matched pairs of 'elective rehabilitation' and 'elective control' hospitals; 197 to rehabilitation and 134 to control. Participating hospitals are listed in the online supplementary appendix. Oneyear follow-up interviews were completed for $94.7 \%$ of surviving randomised patients. Vital status was ascertained at 2 years for $99.9 \%$ and after $7-9$ years for $99.4 \%$ of randomised patients (online only appendix).

\section{Baseline comparisons}

At baseline, patients randomised to rehabilitation and controls were well matched on personal characteristics, clinical histories and lifestyle habits (table 1). A high proportion of patients with a history of insulin-dependent diabetes among controls was almost balanced by a low proportion of patients with a history of non-insulin dependent diabetes. Other measures, including cigarettes/day, frequency and quantity of alcohol consumption, diet (vegetables, whole-meal bread, low fat spread, semi- or skimmed milk, cooking oil, sugar and salt) and exercise score (calculated from estimates of frequency, duration and nature of activities) showed no differences between groups prior to MI (data not presented). Patients in rehabilitation and control groups were very similar also on health-related quality of life (SF36) and PGWB scales, with no significant differences in any of the domains (table 2), and on interviewer's perceived assessment of attitude to life with only $97(11 \%)$ rehabilitation and $106(12 \%)$ control patients judged to have a negative attitude. The characteristics at baseline of rehabilitation and control patients in elective hospitals were also comparable.

\section{Mortality}

At 1 year 101 randomised patients had died; 54 (6.0\%) rehabilitation and $47(5.2 \%)$ control patients, giving a RR of all-cause mortality of 1.16 (95\% CI 0.79 to 1.69$)$. At 2 years 166 patients had died, 82 rehabilitation and 84 control patients with $\mathrm{RR}=0.98$ (95\% CI 0.74 to 1.30 ), and after $7-9$ years, 488 patients had died, 245 randomised and 243 control patients with $\mathrm{RR}=0.99$ (95\% CI 0.85 to 1.15 ) (table 3, figure 1). The corresponding numbers in the elective comparison groups were at 1 year $13(6.6 \%)$ rehabilitation and 7 (5.2\%) control patients, at 2 years 19 rehabilitation and 11 control patients and after 7-9 years 44 rehabilitation and 30 control patients. 
Table 1 Comparison of patients randomised to rehabilitation or control or in rehabilitation or control hospital, at baseline

\begin{tabular}{|c|c|c|c|c|}
\hline \multirow[b]{2}{*}{ Characteristic/medical history/lifestyle habit } & \multicolumn{2}{|c|}{ Randomised controlled trial } & \multicolumn{2}{|l|}{ Elective hospitals } \\
\hline & Rehabilitation, $n=903$ & Control, $\mathrm{n}=\mathbf{9 1 0}$ & Rehabilitation, $n=197$ & Control, $n=134$ \\
\hline Age & Mean (SD) & & & \\
\hline Gender & Number (\%) & & & \\
\hline Men & $656(72.6)$ & 677 (74.4) & $157(79.7)$ & $95(70.9)$ \\
\hline Women & $247(27.4)$ & $233(25.6)$ & $40(20.3)$ & $39(29.1)$ \\
\hline Previous hypertension treated & $222(25.1)$ & $216(24.3)$ & $46(24.5)$ & $28(23.3)$ \\
\hline Untreated & $49(5.5)$ & $38(4.3)$ & $10(5.3)$ & $6(5.0)$ \\
\hline \multicolumn{5}{|l|}{ Previous diabetes } \\
\hline Insulin dependent & $19(2.1)^{*}$ & $36(4.0)^{*}$ & $4(2.1)$ & $2(1.6)$ \\
\hline Non-insulin dependent & $78(8.8)$ & $69(7.7)$ & $23(12.2) \dagger$ & $5(3.9) \dagger$ \\
\hline Smoking & $364(40)$ & $374(41)$ & $80(41)$ & $42(31)$ \\
\hline
\end{tabular}

*Significant difference between randomised groups $\mathrm{p}<0.05$.

†Significant difference between elective groups $p<0.05$.

\section{Morbidity}

Cardiovascular morbidity at 1-year follow-up did not differ between rehabilitation and control groups (table 4). For the combined endpoint (death, non-fatal MI, stroke or revascularisation) the RR was 0.96 (95\% CI 0.88 to 1.07). Re-admissions to hospital among surviving patients for any cardiovascular condition during the year were similar at 222 (25\%) and 239 $(26 \%)$ in rehabilitation and control groups respectively. Medication for cardiovascular disease was similar in the two groups except that long-acting nitrates or calcium channel blockers were taken by fewer rehabilitation than control patients.

\section{Quality of life and PGWB}

The health-related quality of life and PGWB at 1-year follow-up are summarised in table 5 . There were no significant differences between rehabilitation and control groups in any of the eight domains of health-related quality of life (SF36 or the three domains of PGWB. Comparisons of scores at follow-up (table 5) with those at baseline (table 2) indicate that five domains

Table 2 Scores in eight domains of the Short Form 36 (SF36) quality of life scale and three domains of the psychological general well-being (PGWB) scale at first interview, shortly after discharge

\begin{tabular}{|c|c|c|c|c|}
\hline \multirow{2}{*}{$\begin{array}{l}\text { SF36 domain/ } \\
\text { PGWB } \\
\text { domain }\end{array}$} & \multicolumn{2}{|l|}{ Randomised } & \multicolumn{2}{|l|}{ Elective } \\
\hline & $\begin{array}{l}\text { Rehabilitation, } \\
n=903\end{array}$ & $\begin{array}{l}\text { Control, } \\
n=910\end{array}$ & $\begin{array}{l}\text { Rehabilitation, } \\
n=197\end{array}$ & $\begin{array}{l}\text { Control, } \\
n=134\end{array}$ \\
\hline $\begin{array}{l}\text { Physical } \\
\text { functioning }\end{array}$ & $48(23)$ & $48(24)$ & $50(21)$ & $47(23)$ \\
\hline Role-physical & $20(26)$ & $22(27)$ & $17(21)$ & $17(24)$ \\
\hline Role-emotional & $64(43)$ & $67(41)$ & $73(38)$ & $66(41)$ \\
\hline Social functioning & $61(32)$ & $63(31)$ & $62(30)$ & $56(31)$ \\
\hline Mental health & $72(21)$ & $73(21)$ & $76(18)$ & $72(21)$ \\
\hline Energy/vitality & $45(24)$ & $45(24)$ & $47(24)^{*}$ & $41(23)^{*}$ \\
\hline Pain & $74(26)$ & $73(27)$ & $70(26)$ & $64(27)$ \\
\hline Health perception & $65(23)$ & $65(24)$ & $63(23)$ & $63(23)$ \\
\hline Anxiety & $19.2(4.7)$ & $19.0(4.9)$ & $19.3(4.1)$ & $18.6(4.8)$ \\
\hline Depression & $12.6(2.6)$ & $12.6(2.8)$ & $12.8(2.3)$ & $12.5(2.7)$ \\
\hline Positive well-being & $11.3(4.0)$ & $11.3(3.9)$ & $11.1(4.0)^{*}$ & $10.2(3.6)^{*}$ \\
\hline
\end{tabular}

of SF36 improved significantly with time in both groups, the score for role-physical increasing slightly more following rehabilitation than in the control group, with the mean difference (SD) being +49 (35) and +44 (36) in the rehabilitation and control groups, respectively. In contrast PGWB changed little between baseline and follow-up.

\section{Risk factors}

There were no significant differences at 1 year between rehabilitation and control groups in smoking, alcohol consumption or any of the dietary measures (fresh fruit as key marker; data for other dietary measures not presented) but significantly fewer rehabilitation than control patients were exercising $>100 \mathrm{kcal} /$ day (table 6). Smoking, alcohol consumption and dietary measures all showed marked changes between baseline (table 1) and follow-up in both rehabilitation and control groups but there was little change in reported physical exercise.

\section{Exclusions and attendance}

The principal reasons for exclusion (956 potentially eligible patients after excluding early deaths and 'not MI' in a sample of five hospitals) were co-morbidity, frailty or confusion (317, $33 \%$ ), extended hospital stay, readmission or transfer to another hospital $(173,18 \%)$, patient request $(181,19 \%)$ and lived or moved out of area or no fixed abode (94,10\%). Excluded patients

Table 3 Life table: mortality by year and cumulative RR (with number initially at risk in parentheses)

\begin{tabular}{|c|c|c|c|c|c|}
\hline \multirow[b]{2}{*}{ Year } & \multicolumn{2}{|c|}{$\begin{array}{l}\text { Rehabilitation } \\
\text { (903) }\end{array}$} & \multicolumn{2}{|c|}{ Control (910) } & \multirow[b]{2}{*}{ Cumulative RR $(95 \%$ Cl) } \\
\hline & Censored & $\overline{\text { Died }}$ & Censored & $\overline{\text { Died }}$ & \\
\hline 1 & 0 & 54 & 0 & 47 & $1.16(0.79$ to 1.69$)$ \\
\hline 2 & 0 & 28 & 1 & 37 & $0.98(0.74$ to 1.30$)$ \\
\hline 3 & 3 & 22 & 2 & 23 & $0.98(0.76$ to 1.28$)$ \\
\hline 4 & 1 & 20 & 2 & 13 & $1.04(0.82$ to 1.31$)$ \\
\hline 5 & 0 & 32 & 0 & 34 & $1.02(0.83$ to 1.25$)$ \\
\hline 6 & 0 & 39 & 0 & 34 & $1.00(0.84$ to 1.19$)$ \\
\hline 7 & 63 & 32 & 52 & 33 & $1.03(0.88$ to 1.20$)$ \\
\hline 8 & 267 & 15 & 304 & 16 & $1.03(0.88$ to 1.21$)$ \\
\hline 9 & 324 & 3 & 306 & 6 & $0.99(0.85$ to 1.15$)$ \\
\hline
\end{tabular}




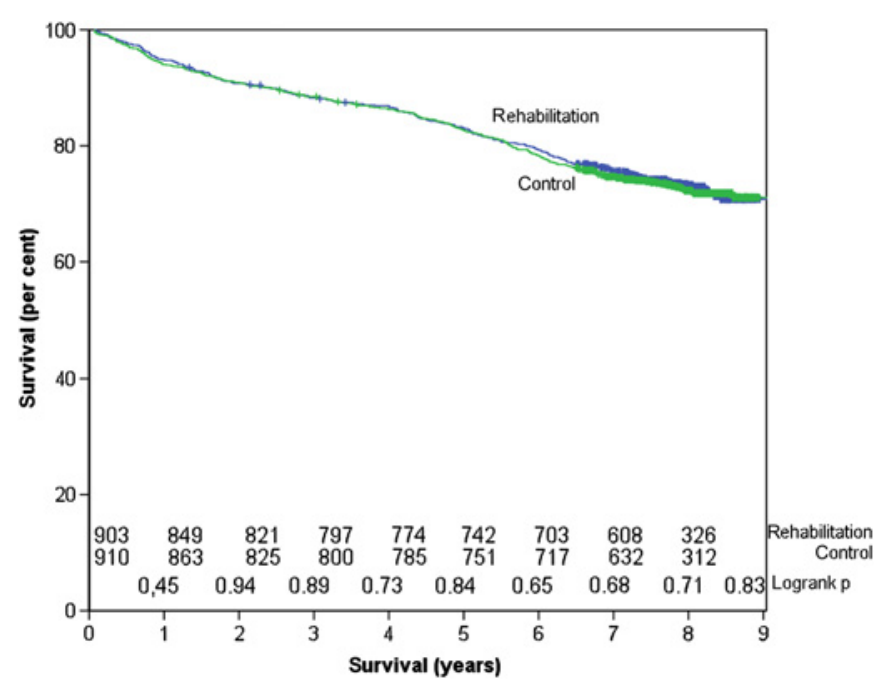

Figure 1 Survival following admission for acute myocardial infarction.

(sample of 641 'potentially eligible' with admission clinical data) were older than admitted patients (mean 68, SD 13 compared with 64,11$)$, more were women $(238,37 \%$ compared with 559 , $26 \%)$, more had histories of MI $(161,26 \%$ compared with 270 , $13 \%)$, angina $(266,41 \%$ compared with $508,24 \%$ ) or diabetes (116, 18\% compared with 236, 11\%), and more experienced infarct complications, for example, left ventricular failure (264, $45 \%$ compared with 422, 21\%). Among patients offered rehabilitation, significantly fewer older patients (65 years and over) attended (192, 72\% compared with $260,82 \%)$ but those who did were as likely as younger patients to attend five or more sessions. Patients' principal reasons for not attending or dropping out were lack of interest (62,8\%), illness $(57,7 \%)$, transport difficulties $(40,5 \%)$, return to work $(17,2 \%)$ and holidays $(13,2 \%)$.

\section{Patient and programme characteristics}

Subset analyses to identify characteristics of patients who might benefit from rehabilitation or of programmes that might be more effective should be interpreted with caution, because of relatively small numbers in subsets and the null outcome of the trial as a whole. There were non-significant trends towards reduced risk of mortality for those randomised to rehabilitation among women and among patients with prior history of angina but not with respect to age, other past medical history or infarct complications. Analysis by hospital showed non-significant trends towards reduced mortality in longer programmes $(>21 \mathrm{~h}$ total and/or $>8$ weeks' duration) and increased mortality in programmes with smaller classes ( $<13$ patients per group).

\section{Patient opinion}

Patients referred to rehabilitation appreciated the programmes, the majority rating seven of eleven elements (information on heart disease, risk factors, medication, advice on diet, exercise training, relaxation training and stress management training) very or fairly helpful on a four-point scale. The majority $(>73 \%)$ of control patients, although they knew of the existence of the rehabilitation programmes, did not feel the need for further advice, support or training in any of the same 11 areas, while a minority would have appreciated more, ranging from $198(27 \%)$ resuscitation training down to 29 (4\%) advice on alcohol consumption. The most commonly proffered (unsolicited) comment was a wish for closer follow-up by doctors, including GPs.

\section{Two-year follow-up}

The 2-year follow-up involved fewer patients (483 rehabilitation and 484 control) because of early trial closure (see Discussion). The only significant difference was that more rehabilitation than control patients reported recent angina (table 7). There were no significant differences in use of statins, general health or opinion of overall care and support after their heart attack; only $23(5 \%)$ rehabilitation and $26(6 \%)$ control patients rated aftercare as poor.

\section{DISCUSSION}

\section{History and need for evidence}

The present trial was commissioned in 1996 with a view to evaluate rehabilitation in the context of the new era of MI

Table 4 Cardiovascular morbidity between discharged and 12-month follow-up and medication for cardiovascular disease at 12-month follow-up

\begin{tabular}{|c|c|c|c|c|}
\hline \multirow[b]{2}{*}{ Morbidity/medication } & \multicolumn{2}{|l|}{ Randomised } & \multicolumn{2}{|l|}{ Elective } \\
\hline & Rehabilitation, $n=795$ & Control, $\mathrm{n}=811$ & Rehabilitation, $n=162$ & Control, $n=115$ \\
\hline Myocardial infarction (MI) & $31(3.9)$ & $39(4.8)$ & $7(4.3)$ & $8(7.0)$ \\
\hline Cerebrovascular accident (stroke) & $6(0.8)$ & $11(1.4)$ & 0 & $1(0.9)$ \\
\hline CABG & $44(5.5)$ & $43(5.3)$ & $7(4.3)$ & $8(7.0)$ \\
\hline PTCA & $38(4.8)$ & $44(5.4)$ & $13(8.0)$ & $9(7.8)$ \\
\hline Combined cardiac outcomes (MI, stroke, CABG, PTCA) & $104(13.1)$ & $127(15.7)$ & $24(14.8)$ & $25(21.7)$ \\
\hline Other hospital admission for heart disease & $118(14.8)$ & $112(13.8)$ & $23(14.2)$ & $16(13.9)$ \\
\hline Any admission for heart disease (MI, stroke, CABG, PTCA, other) & $222(30)$ & $239(29)$ & $47(29)$ & $41(36)$ \\
\hline Angina in past 4 weeks & $242(31)$ & $244(31)$ & $51(31)$ & $35(31)$ \\
\hline GP visits in past 4 weeks & $375(48)$ & $383(48)$ & $86(53)$ & $60(52)$ \\
\hline Aspirin & $713(91)$ & $719(90)$ & $153(94)$ & $101(88)$ \\
\hline$\beta$ blocker & $432(54)$ & $443(55)$ & $106(66)$ & $77(68)$ \\
\hline ACE inhibitor & $360(45)$ & $356(44)$ & $67(42)$ & $47(41)$ \\
\hline Diuretic & $200(25)$ & $221(27)$ & $53(33)$ & $39(34)$ \\
\hline Long acting nitrate/calcium channel blocker & $333(42)^{*}$ & $388(48)^{*}$ & $66(41) \dagger$ & $26(23) \dagger$ \\
\hline GTN medication in last week & $191(24)$ & $206(25)$ & $34(21)$ & $30(26)$ \\
\hline Statin & $468(59)$ & $500(62)$ & $126(78) \dagger$ & $70(61) \dagger$ \\
\hline
\end{tabular}

\footnotetext{
Data are expressed as number (\%).
}

* Significant difference between randomised groups $\mathrm{p}<0.05$.

†Significant difference between elective groups $p<0.01$.

CABG, coronary artery bypass graft; GP, general practitioner; GTN, glyceryl trinitrate; PTCA, percutaneous transluminal coronary angioplasty. 
Table 5 Scores in eight domains of the SF36 quality of life scale and three domains of the PGWB scale at 12-month follow-up

\begin{tabular}{|c|c|c|c|c|}
\hline \multirow[b]{2}{*}{$\begin{array}{l}\text { SF36 domain/PGWB } \\
\text { domain }\end{array}$} & \multicolumn{2}{|l|}{ Randomised } & \multicolumn{2}{|l|}{ Elective } \\
\hline & $\begin{array}{l}\text { Rehabilitation, } \\
\mathrm{n}=795\end{array}$ & $\begin{array}{l}\text { Control, } \\
\mathrm{n}=\mathbf{8 1 1}\end{array}$ & $\begin{array}{l}\text { Rehabilitation, } \\
\mathrm{n}=162\end{array}$ & $\begin{array}{l}\text { Control, } \\
n=115\end{array}$ \\
\hline Physical functioning & $65(29)$ & $64(30)$ & $69(26)$ & $64(28)$ \\
\hline Role-physical & $69(31)$ & $67(33)$ & $69(29)$ & $69(31)$ \\
\hline Role-emotional & $85(23)$ & $85(25)$ & $86(25)$ & $88(23)$ \\
\hline Social functioning & $81(28)$ & $79(29)$ & $82(27)$ & $84(28)$ \\
\hline Mental health & $76(13)$ & $76(13)$ & 77 (14) & $78(13)$ \\
\hline Energy/vitality & $65(24)$ & $65(24)$ & $66(26)$ & $68(25)$ \\
\hline Pain & $69(28)$ & $68(29)$ & $67(26)$ & $66(28)$ \\
\hline Health perception & $58(25)$ & $57(25)$ & $57(24)$ & $58(25)$ \\
\hline Anxiety & $19.8(4.4)$ & $19.8(4.7)$ & $19.6(4.7)$ & $20.2(5.1)$ \\
\hline Depression & $12.3(3.9)$ & $12.3(3.8)$ & $13.0(2.5)$ & $13.3(2.7)$ \\
\hline Positive well-being & $13.0(2.6)$ & $12.9(2.7)$ & $12.2(3.9)$ & $12.4(4.2)$ \\
\hline
\end{tabular}

Data are expressed as mean (SD).

PGWB, psychological general well-being; SF36, Short Form 36

management. The rehabilitation provision in UK was expanding (from initially few centres), although without contemporary

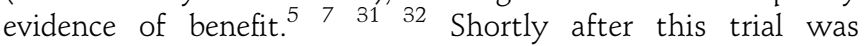
commissioned, guidelines were written advocating rehabilitation and it became more widely accepted as playing a role in the overall clinical management of cardiac patients. ${ }^{23}$ However, the evidence underpinning guidelines was never quite as strong as it has come to be believed, being based largely on the metaanalyses of small and early trials ${ }^{9}$ rather than on any large and recent trial. The need for contemporary evidence of the effectiveness of rehabilitation remained.

\section{Trial size}

This was a randomised controlled trial of comprehensive rehabilitation in 1813 patients following acute MI as provided in typical programmes in representative hospitals in England and Wales in 1997-2000. The groups randomised to rehabilitation and to control were well-matched. Patient assessments at baseline and at follow-up were undertaken 'blind' by trained researchers independently of care providers, outcome measures were objective, including all-cause mortality, further cardiovascular events and used validated structured questions and scales. Results for 331 patients in the pre-planned elective hospitals comparison are analysed separately and presented alongside. The trial enrolled fewer hospitals and recruited fewer patients than planned, because the funding body (NHS) requested early closure, when 23 hospitals had agreed to randomise (24 districts had granted ethical approval) and discussions over joining were progressing with others. Nevertheless, it is the only randomised multi-centre trial to evaluate post infarct comprehensive rehabilitation in the modern era of early thrombolysis, short hospital

Table 6 Lifestyle habits at 12-month follow-up

\begin{tabular}{|c|c|c|c|c|}
\hline \multirow[b]{2}{*}{ Lifestyle habit } & \multicolumn{2}{|l|}{ Randomised } & \multicolumn{2}{|l|}{ Elective } \\
\hline & $\begin{array}{l}\text { Rehabilitation, } \\
\mathrm{n}=795\end{array}$ & $\begin{array}{l}\text { Control, } \\
\mathrm{n}=\mathbf{8 1 1}\end{array}$ & $\begin{array}{l}\text { Rehabilitation, } \\
n=162\end{array}$ & $\begin{array}{l}\text { Control } \\
n=115\end{array}$ \\
\hline Smoking & $137(17)$ & $140(17)$ & $30(18)$ & $21(18)$ \\
\hline $\begin{array}{l}\text { Drinking (moderate } \\
\text { and heavy) }\end{array}$ & $80(10)$ & $82(10)$ & $14(9)$ & $10(9)$ \\
\hline Diet (fresh fruit daily) & $537(68)$ & $521(65)$ & $106(65)$ & $73(64)$ \\
\hline $\begin{array}{l}\text { Physical exercise } \\
\text { (>100 kcal/day) }\end{array}$ & $67(9)^{*}$ & $98(12)^{*}$ & $23(14)$ & $15(13)$ \\
\hline
\end{tabular}

Data are expressed as number (\%).

${ }^{*}$ Significant difference between randomised groups $\mathrm{p}<0.05$.
Table 7 Brief telephone follow-up at 2 years (randomised trial)

\begin{tabular}{lcc}
\hline & $\begin{array}{c}\text { Rehabilitation, } \\
\mathbf{n = 4 8 3}\end{array}$ & $\begin{array}{c}\text { Control, } \\
\mathbf{n = 4 8 4}\end{array}$ \\
\hline Further MI & $12(2)$ & $7(1)$ \\
Stroke & $5(1)$ & $2(-)$ \\
CABG & $20(4)$ & $24(4)$ \\
PTCA & $15(3)$ & $11(2)$ \\
Angina in past 4 weeks & $135(28)^{*}$ & $102(21)^{*}$ \\
Aspirin & $416(87)$ & $418(87)$ \\
Statin & $312(66)$ & $331(70)$ \\
Smoking & $63(13)$ & $59(12)$ \\
General health: good, very good, & $313(65)$ & $317(66)$ \\
excellent & & $119(30)$ \\
Change in year: better, much better & $109(29)$ & $406(86)$ \\
Opinion of care: good, very good & $393(84)$ & \\
\hline Data are expressed as number (\%). & & \\
*Significant difference p<0.05. &
\end{tabular}

stay and extensive medication for secondary prevention. Although the trial is smaller than planned, the numbers exceed the 'sample size' estimate for quality of life measures and, with the follow-up extended to 7-9 years, also achieve a post hoc 'sample size' estimate for a somewhat lower 80\% 'power' ( $\beta=0.20)$ of detecting with significance $(\alpha=0.05)$ the $20 \%$ difference in RR of mortality, anticipated at design.

\section{Trial findings}

The trial showed no benefit of rehabilitation on all-cause mortality at 1 year, 2 years or after 7-9 years and no major effect on morbidity, quality of life, PGWB or lifestyle at 1 year. The only statistically significant differences (among 43 comparisons) were a slightly better improvement (change between baseline and follow-up) in the 'role-physical' score of SF36, possibly compatible with reports of changes in physiological measures, ${ }^{53}$ a reduced proportion receiving long-acting nitrate or calcium channel blocker medication but fewer reporting $>100 \mathrm{kcal}$ of daily physical exercise in the rehabilitation group-findings which could have occurred by chance. ${ }^{5} 33$ The absence of effect on lifestyles suggests that rehabilitation added little to contemporary patients' knowledge and motivation to make prudent changes. The modest trend towards better outcome in longer programmes might suggest that typical UK programmes were insufficiently intense but the trend was not significant and no dose-response has been reported in previous trials.

\section{Potential limitations}

The potential limitations of the trial include the premature closure but despite this numbers were adequate to have shown significant differences if present. As a trial analysed by 'intention to treat' some cross contamination might have diluted a 'true' treatment effect between rehabilitation and control groups but would be unlikely to remove it completely. Attendance was comparable with ongoing national audits. ${ }^{34}$ Loss to follow-up was unlikely to have affected the findings as vital status at 2 years was known for all but one patient ('right censored' for emigration) and follow-up interviews were completed in $95 \%$ of surviving patients in both groups. Patient selection was also unlikely to dilute a 'true' effect, since subgroup comparison, albeit with limited power in a trial of this size, showed no statistically significant differences in outcome by age, sex, clinical history or infarct complication. The findings relate to comprehensive cardiac rehabilitation following acute MI, 
provided in typical programmes in representative British hospitals some 10 years ago. However, the content of programmes has changed little since then ${ }^{35}$ and the major advances in medical management, excepting primary coronary angioplasty, had taken place before this trial was conducted.

\section{Comparison with other trials}

The conclusion that rehabilitation in the modern era of medical management does not reduce mortality or morbidity and has no beneficial effect on psychosocial well-being or lifestyle appears to differ from those of reviews of previous trials, ${ }^{78}$ which underpin the guidelines, ${ }^{2}{ }^{3}$ The Cochrane review found an OR for allcause mortality of 0.73 (95\% CI 0.54 to 0.98 ) in 12 exercise only trials and of 0.87 (95\% CI 0.71 to 1.05$)$ in 28 comprehensive rehabilitation trials ${ }^{8}$ and, subsequently, combining exercise and comprehensive programmes, reported an OR of 0.80 (95\% CI 0.68 to 0.93$).{ }^{9}$ The evidence that rehabilitation reduced mortality rests on meta-analyses ${ }^{36}$ (with consequent limitations $)^{37} 38$ of predominantly small trials undertaken over several decades and not on any large or recent trial. ${ }^{36-38}$ Meta-analyses are weighted by trials undertaken in the 1960s and 1970s, when mortality was relatively high. Modern medical management of acute MI has been transformed since early trials and post infarct mortality has fallen significantly. The present findings are consistent with the negative outcomes of the only other recent trial with comparable numbers of patients (albeit including other cardiac conditions with $\mathrm{MI})^{39}$ and of meta-analysis of trials conducted since the WHO collaborative (which itself was inconclusive) reported in $1983 .{ }^{11}$ They are consistent also with the absence of significant effect on mortality or morbidity in the only two recent multi-centre trials enrolling $>2000$ patients, both of psychological intervention without exercise training, ${ }^{40} 41$ a long term follow-up of the 'national' trial ${ }^{42}$ and possibly also with the observation that supervised centre-based rehabilitation gives no significant benefit over 'do-it-yourself' rehabilitation at home. ${ }^{43}$ Publication bias cannot be ruled out ${ }^{44}$ but is unlikely to explain both time trend and significance among exercise only and non-significance among comprehensive programmes.

\section{Differences in context between historical and recent trials}

The benefit of rehabilitation appears to have declined as medical management has advanced. In early trials exercise training may have helped overcome physical de-conditioning, associated with prolonged bed-rest ${ }^{12}$ but now largely precluded by shorter bedrest and earlier discharge. ${ }^{13}$ Referral to rehabilitation in $1960 \mathrm{~s}$ and 1970s may have led to better uptake of secondary prevention, when aspirin and $\beta$-blockers (unrecorded in rehabilitation trials of the period) were being introduced. ${ }^{16}{ }^{17}$ Rehabilitation programmes may have been more effective in encouraging patients to make beneficial lifestyle changes, when lifestyle factors were not so widely accepted as they are now by the public at large. That people know what they should do and actually do when they become patients is supported by significant changes in lifestyle among controls as well as patients referred to rehabilitation in the present trial and in previous trials. ${ }^{40}$ More intensive rehabilitation, for example, 3 weeks as inpatients as provided in some countries, may be more effective but such programmes have not been evaluated by randomised trials. Rehabilitation with extended exercise training may be more effective ${ }^{46}$ and more relevant for patients with heart failure $^{47}$ and a long term (3-year) programme of multifactorial education and behavioural intervention may offer benefits. ${ }^{48}$ There remains a possible role for an outpatient programme as a 'vehicle' for enhancing secondary prevention measures, as, for example, in the EUROACTION study. ${ }^{49} 50$

\section{CONCLUSION}

This multi-centre trial of comprehensive rehabilitation following acute MI in a representative sample of hospitals in England and Wales found no effect on mortality at 1 year, 2 years or after 7-9 years and little evidence of any beneficial effect on morbidity, cardiac medication, risk factors, lifestyle or patients' appreciation of total aftercare. This finding differs from those meta-analyses, weighted by early trials, which suggested benefits including reduced mortality (as still widely believed), but is consistent with meta-analyses of trials undertaken since 1983. As medical management has evolved over the past $30-40$ years the scope for benefit from cardiac rehabilitation appears to have declined. Rehabilitation programmes may contribute to 'seamless patient care' and they are appreciated by many patients but evidence of objective benefit is weak relative to the proven benefits from other aspects of cardiac management. The main role of cardiac rehabilitation programmes after MI now may be to provide a vehicle for secondary prevention, though no such benefit was found in this trial.

Acknowledgements Advisory group: Hugh Bethell, Lorna Cay, Andrew Coats, Chris Davidson, Belinda Linden, Andrew Steptoe, Sally Turner. Research officers: Andrew Beswick, Elaine Matthews, Julia Townson. Consultant physicians/cardiologists, rehabilitation staff and research interviewers (online appendix), records departments and ONS and last but not least many patients for agreeing to take part in the trial.

Funding This study was funded by the NHS Research and Development Programme (northern region) (RM19) and the Heart research fund for Wales.

Competing interests None.

Patient consent Obtained

Ethics approval Ethics approval was provided by South Glamorgan, Oxford and Anglia Multi-centre Research Ethics Committee for all the participating centres.

Contributors RW: design, management, follow-up, analysis, report; DJ: design, early management, interviewer training; AH: revision of report.

Provenance and peer review Not commissioned; externally peer reviewed.

\section{REFERENCES}

1. World Health Organization (WHO). Rehabilitation of Patients With Cardiovascular Disease; Report of WHO Expert Committee; WHO Tech Rep Series 270. Copenhagen World Health Organization (WHO), 1969

2. Department of Health. National Service Framework for Coronary Heart Disease. London: Department of Health, 2000.

3. Scottish Intercollegiate Guidelines Network (SIGN). Guideline 57 Cardiac Rehabilitation. Edinburgh: SIGN, 2002.

4. Giannuzzi P, Saner H, Bjornstad H, et al. Secondary prevention through cardiac rehabilitation; position paper of the working group on cardiac rehabilitation and exercise physiology of the European Society of Cardiology. Eur Heart $J$ 2003;24:1273-8

5. World Health Organization (WHO). Rehabilitation and Secondary Prevention After Acute Myocardial Infarction (Euro report 84). Copenhagen: WHO, 1983.

6. Shaw LW. Effects of a prescribed supervised exercise program on mortality and cardiovascular morbidity in patients after a myocardial infarction. The National Exercise and Heart Disease Project. Am J Cardiol 1981:48:39-46.

7. Oldridge NB, Guyatt GH, Fischer ME, et al. Cardiac rehabilitation after myocardial infarction; combined experience of randomized clinical trials. JAMA 1988:260:945-50.

8. Jolliffe JA, Rees K, Taylor RS, et al. Exercise-based rehabilitation for coronary heart disease. Cochrane Database Syst Rev 2000;(4):CD001800.

9. Taylor RS, Brown A, Ebrahim S, et al. Exercise based rehabilitation for patients with coronary heart disease: systematic review and meta-analysis of randomised controlled trials. Am J Med 2004;116:682-92.

10. West RR. Trials are Not Large Enough. Leuven: European Society of Cardiology, 2005.

11. Julian DG. The history of coronary care units. Br Heart J 1987:57:497-502

12. Levine SA, Lown B. "Armchair" treatment of acute coronary thrombosis. J Am Med Assoc 1952;148:1365-9.

13. West RR, Henderson AH. A randomised multi-centre trial of early mobilisation afte uncomplicated myocardial infarction. Br Heart J 1979;42:381-5. 
14. Anon. Randomised trial of intravenous streptokinase, oral aspirin, both, or neither among 17,187 cases of suspected acute myocardial infarction: ISIS-2. ISIS-2 (Second International Study of Infarct Survival) Collaborative Group. Lancet 1988:2:349-60.

15. Weaver WD, Simes RJ, Betriu A, et al. Comparison of primary coronary angioplasty and intravenous thrombolytic therapy for acute myocardial infarction; a quantitative review. JAMA 1997:278:2093-8.

16. Elwood PC, Cochrane AL, Burr ML, et al. A randomised controlled trial of acetyl salicylic acid in secondary prevention of mortality from myocardial infarction. Br Med J 1974:1:436-40.

17. Anon. Reduction in mortality after myocardial infarction with long-term betaadrenoceptor blockade. Multicentre international study: supplementary report. $\mathrm{Br}$ Med J 1977:2:419-21.

18. Anon. Indications for ACE inhibitors in the early treatment of acute myocardial infarction: systematic overview of individual data from 100,000 patients in randomized trials. ACE Inhibitor Myocardial Infarction Collaborative Group. Circulation 1998:97:2202-12

19. Anon. Randomised trial of cholesterol lowering in 4444 patients with coronary heart disease: the Scandinavian Simvastatin Survival Study (4S). Lancet 1994;344:1383-9.

20. Coats A, McGee H, Stokes H, et al, eds. BACR Guidelines for Cardiac Rehabilitation. Oxford: Blackwell, 1995.

21. Ware JE Jr, Sherborne CD. The MOS 36-item short-form health survey (SF-36). Conceptual framework and item selection. Med Care 1992;30:473-83.

22. Ware JE, Snow KK, Kosinski MA, et al. SF36 Health Survey: Manual and Interpretation Guide. Boston, MA: New England Medical Centre. The Health Institute, 1993.

23. Jenkinson C, Layte R, Wright $\mathrm{L}$, et al. The UK SF36 an Analysis and Interpretation Manual: A Guide to Health Status Measurement With Particular Reference to The Short Form 36 Health Survey. Oxford: Oxford University, 1996.

24. Dupuy H. The Psychological General Well-being (PGWB) Index. In: Wenger NK Mattson ME, Furberg CD, et al, eds. Assessment of Quality of Life In Clinical Trials of Cardiovascular Therapies. Greenwich, Conn: Le Jacq Publishers Inc., 1984.

25. Office of Population Censuses and Surveys. General Household Survey 1978 London: HMSO, 1980.

26. Office of Population Censuses and Surveys. General Household Survey 1972. London: HMSO, 1975.

27. Ministry of Agriculture, Fishery and Food. Dietary and Nutritional Survey of British Adults. London: HMSO, 1990.

28. Taylor HL, Jacobs DR Jr, Schucker B, et al. A questionnaire for the assessment of leisure time physical activities. J Chronic Dis 1978;31:741-55.

29. Office of Population Censuses and Surveys. General Household Survey 1987 London: HMSO, 1989

30. West RR. Cardiac rehabilitation. In: Pitt B, Julian D, Pocock S, eds. Clinical Trials in Cardiology. London: WB Saunders, 1997.

31. Horgan J, Bethell H, Carson $\mathrm{P}$, et al. British Cardiac Society working party report on cardiac rehabilitation. Br Heart J 1992;67:412-18.

32. Bethell HJ, Turner SC, Evans JA, et al. Cardiac rehabilitation in the United Kingdom; how complete is the provision? J Cardiopulm Rehabil 2001:21:111-15.

33. Lee BC, Hsu HC, Tseng WY, et al. Effect of cardiac rehabilitation on angiogenic cytokines in postinfarction patients. Heart 2009;95:1012-18.

34. Bethell H, Lewin R, Evans J, et al. Outpatient cardiac rehabilitation attendance in England: variability by region and clinical characteristics. J Cardiopulm Rehabil Prev 2008;28:386-91.
35. Bethell H, Lewin R, Dalal H. Cardiac rehabilitation in the United Kingdom. Heart 2009;95:271-5.

36. Peto R. Why do we need systematic overviews of randomized trials? Stat Med 1987:6:233-44.

37. Thompson SG, Pocock SJ. Can meta-analyses be trusted? Lancet 1991;338:1127-30.

38. West R. Assessment of evidence versus consensus or prejudice. J Epidemiol Community Health 1992; $\mathbf{4 6 : 3 2 1 - 2 .}$

39. Zwisler AD, Soja AM, Rasmussen S, et al: DANREHAB Group. Hospital-based comprehensive cardiac rehabilitation versus usual care among patients with congestive heart failure, ischemic heart disease, or high risk of ischemic heart disease: 12-month results of a randomized clinical trial. Am Heart $J$ 2008;155:1106-13.

40. Jones DA, West RR. Psychological rehabilitation after myocardial infarction; multicentre randomised controlled trial. BMJ 1996:313:1517-21.

41. Berkman LF, Blumenthal J, Burg M, et al; Enhancing Recovery in Coronary Heart Disease Patients Investigators (ENRICHD). Effects of treating depression and low perceived social support on clinical events after myocardial infarction: the Enhancing Recovery in Coronary Heart Disease Patients (ENRICHD) Randomized Trial. JAMA 2003:289:3106-16.

42. Dorn J, Naughton J, Imamura D, et al. Results of a multicenter randomized clinical trial of exercise and long-term survival in myocardial infarction patients: the National Exercise and Heart Disease Project (NEHDP). Circulation 1999:100:1764-9.

43. Dalal HM, Zawada A, Jolly K, et al. Home-based versus centre-based cardiac rehabilitation: Cochrane systematic review and meta-analysis. BMJ 2010;340: b5631.

44. Trikalinos TA, Churchill R, Ferri M, et al; EU-PSI project. Effect sizes in cumulative meta-analyses of mental health randomized trials evolved over time. J Clin Epidemiol 2004; 57:1124-30.

45. West RR, Evans DA. Lifestyle changes in long term survivors of acute myocardial infarction. J Epidemiol Community Health 1986:40:103-9.

46. Plüss CE, Billing E, Held C, et al. Long-term effects of an expanded cardiac rehabilitation programme after myocardial infarction or coronary artery bypass surgery: a five-year follow-up of a randomized controlled study. Clin Rehabil 2011:25:79-87.

47. O'Connor CM, Whellan DJ, Lee KL, et al; for HF-ACTION Investigators. Efficacy and safety of exercise training in patients with chronic heart failure: HF-ACTION randomized controlled trial. JAMA 2009;301:1439-50.

48. Giannuzzi P, Temporelli PL, Marchioli R, et al: for the GOSPEL Investigators. Global secondary prevention strategies to limit event recurrence after myocardia infarction: Results of the GOSPEL study, a multicenter, randomized controlled trial from the Italian Cardiac Rehabilitation Network. Arch Intern Med 2008; 168:2194-204.

49. Cooper A, Skinner J, Nherera L, et al. Clinical Guidelines and Evidence Review for Post Myocardial Infarction: Secondary Prevention in Primary and Secondary Care for Patients Following a Myocardial Infarction. London: National Collaborating Centre for Primary Care and Royal College of General Practitioners, 2007.

50. Wood DA, Kotseva K, Connolly S, et al; EUROACTION Study Group. Nursecoordinated multidisciplinary, family-based cardiovascular disease prevention programme (EUROACTION) for patients with coronary heart disease and asymptomatic individuals at high risk of cardiovascular disease: a paired, clusterrandomised controlled trial. Lancet 2008;371:1999-2012. 